\title{
POTENTIAL INJURY MECHANISMS TO THE CLIMBER'S BELAYER
}

\author{
P. A. BUTLIN, MA
}

Department of P.E. and Creative Studies, Sunderland Polytechnic

\section{ABSTRACT}

Photographs and transparencies of the techniques used in belaying, combined with information gained from discussions amongst experienced climbers, provided evidence of the potential injury mechanisms which may be subjected to the belayer in having to arrest a falling climber, whilst moving towards the belayer.

\section{INTRODUCTION}

Injuries sustained by the moving climber while experiencing a fall have been well documented, Jones (1976), and by the German Alpine Federation (1971-73). Mechanical theory has quantified the loading to which the climber's body may be subjected (Wexler, 1950; Cumming and Slesser, 1958). Examinations have also been made of the various types of injury caused by different rope attachments, by Steele (1976) and Schubert (1971-73).

The knowledge that the human body and its components can withstand a variety of forces without severe trauma is of major importance in the art of rock climbing. The limits at which bones fracture when subjected to forces from various directions can be found in the literature of Kummer (1972), of Evans (1973), and of Reilly and Burstein (1974). References of known injuries to the belaying climber, whilst arresting a fall would have been useful knowledge to the extent and nature of the problem. However, such evidence was not available and therefore the purpose of this work was to investigate the potential injury mechanisms regarding this aspect of climbing.

The investigation focussed upon the climber moving towards the belayer and made no attempt to consider the complications which the belayer may have, in arresting a falling climber, who has climbed away from the belayer.

\section{METHOD}

Climbers were observed during ascent and photographic evidence of the belayer's techniques was collected. Particular attention was paid to the manner in which the belayer's body was used as a friction device in addition to the positions of the point of anchorage and the moving climber's rope relative to the belayer. Transparencies were made and projected onto a white card in order to mark the directional line of force acting on the belayer, when a falling climber had to be arrested. Although it was not possible to give the absolute magnitude of the resultant force (this being dependant upon the severity of the fall, as outlined by Wexler (1950), and by Cumming and Slesser (1958)), it was possible to give the relative magnitude and its direction in relation to the forces acting through the ropes. Using the photographic techniques, combined with information gained in discussions with experienced climbers, several potential injury mechanisms were identified.

\section{RESULTS AND DISCUSSIONS}

Potential injury mechanisms when the belayer's body is used as a friction device - burns, fractures and dislocations

The belayer's body in many cases is used as a friction device which allows the rope attached to the climber (active rope) to slide with friction, thus bringing the falling climber to rest under control and without shock loading to his body. Such a technique also has the advantage of reducing the rate of loading on the belayer's skeleton. However, this method of rope control can be a potential source of injury to the belayer. In some cases the waist and upper torso was used (Plates 1 and 2), whilst in others, the rope was coiled around his bare flesh. The fall, not held instantaneously, would have resulted in severe burns to the belayer's body. Another belayer had the rope which was attached to the moving climber coiled around his lead arm (Plate 4). A fall in this case would have not only resulted in rope burns around the bare forearm but in addition could have placed undue stresses, of a torsional nature upon the belayer's forearm. The result of such torsion stresses would likely produce either a spiral fracture of the radius and ulna, or a fracture dislocation of the radial head.

Climbers who use metal friction devices through which the rope slip can be controlled no longer experience these injuries. However, because of expense or inexperience many climbers use the body as the friction device and therefore it is necessary for suitable clothing to be worn and correct techniques to be performed.

Potential injury mechanisms due to the point of achorage - fractures, dislocations and internal injuries (primary)

Several climbers were observed with the point of anchorage situated below waist level (Fig. 2) (Plates 5 and 6).

In this case the resultant force ' $R$ ' is vertically downwards through the hips and consequently distributed to each leg. The magnitude of this resultant force will be of the order of 68 percent greater than that of the tensions in either rope. Such a magnitude of resultant could, in this case, cause injury to the hip or pelvic girdle.

If, however, the lead leg were to be in line with this resultant and the fall to be of a severe shock loading on the belayer's body, the bones of the lead leg could at some point fracture. Column fractures of the tibia have been mentioned in discussions with climbers who have witnessed this incident.

Two methods of avoiding this injury are shown in Fig. 1 and Fig. 3.

Fig. 1 illustrates the point of anchorage ' $A$ ' situated above waist level. In this case the resultant force ' $R$ ' is of a magnitude 33 percent less than that of either rope. By dropping the body slightly and bringing the hands close towards the leading thigh, the belayer could bring the two ropes further into line. The lead leg in the figure is flexed slightly in preparation for any shock loading which may take place. This would enable him to bring a fall under control without fear of injury to himself.

Fig. 3 illustrates the belayer sitting on the edge of the rock and the resultant force ' $R$ ' directed through the femurs of both legs. The magnitude has once again been reduced but is still in the order of $\mathbf{3 3}$ percent greater than that in either rope. However, the sitting position helps to avoid undue compressional stress upon the belayer's legs as most of this 
force is likely to be transmitted through the vertebral column and/or pelvis which are suitably supported by the rock. Even so, if the compressional force due to the falling climber was of high magnitude, the pressure subjected to the intervertebral discs may be the cause of injury at the lower lumbar and lumbo-sacral spine region. It is important to note that sitting positions produce greater disc pressure than standing positions (Wirhed, 1984).

Fig. 4 illustrates a view from above the belayer where the climber has traversed in the direction of the arrow. If the belayer makes no adjustment to his stance the active rope ' $C$ ' is now no longer in line with the anchor rope as shown by the dotted line. A fall occurring at this point would in addition to the compressional forces also subject the belayer's body to torsional forces ' $T$ '.

Because of the attachment of the anchor and active ropes to the waist any loading of the lower limb bones is likely to be compressive and tensile (extensive) stress will not occur. A possible exception would be if the belayer's foot was caught in the active rope and the pull of the two ropes were in line. This situation is not beyond reality and warns the belayer to keep the active rope taut and to keep rope taken up, well away from the feet. Tensile strength of bone is approximately half that of its compressive strength according to Kummer (1972), and Evans (1973) and the belayer is warned to avoid this situation ever arising.

The forces most common to the belayer are compressive and although bone is stronger in compression than in tension bad points of rope anchorage can provide magnitudes of compressive force high enough for fractures to occur. The compressive strength of the tibia is $23,880 \mathrm{lb}^{2}{ }^{2}$ (1681 kg.cm²) $\left(16,474\right.$ N.cm²) to $29,700 \mathrm{lb} . i n^{2}\left(2091 \mathrm{~kg} . \mathrm{cm}^{2}\right)(20,492$ N.cm ${ }^{2}$ ) according to Kummer (1972) and these figures are given when the loading is parallel to the shaft of the bone but can be reduced, when loading is applied at various angles. If the compressional forces are also combined with torsional forces then fractures can be of greater severity.
This preliminary investigation has focussed upon the injuries sustained by the belayer whilst the climber moves towards the belayer. Investigations are now being carried out on the potential injury mechanisms which may arise whilst the climber moves away from the belayer.

\section{CONCLUSIONS}

The belayer's stance and his point of anchor rope attachment must be best suited to meet the demands of a fall immediately it takes place. The clothing he wears, when using his body as a friction device, must be suitable for dealing with any rope slip.

'The true strength in a climbing rope lies in its intelligent use' (Tarbuck, 1947). Further studies such as this, will help improve the techniques of climbers, minimise injuries and also explain the injuries which can occur if the correct procedures are not executed.

\section{References}

Cumming, I. G. and Slesser, C. G. M., 1958 "Evaluation of a risk". Scottish Mountaineering Club J. 26: 149: 254-259.

Evans, F. G., 1973. Mechanical Properties of Bone. 1st Edition, Charles C. Thomas, Illinois.

German Alpine Federation D.A.C. 1971-73. Safety Report. German Alpine Club, Munich.

Jones, I., 1976 "Methods of rope attachment". Climber and Rambler, April, Letters to the Editor.

Kummer, B. K. F. and Fung, Y. C. (Ed.), 1972. Biomechanics of Bone. Biomechanics: Its Foundations and Objectives. 1st Edition, Prentice Hall, New Jersey.

Reilly, D. T. and Burnstein, A. H., 1974 "The mechanical properties of cortical bones". J.Bone Joint.Surg. 56-A: 1001-1021.

Schubert, P., D.A.V., 1971-73 "Is there such a thing as a statically active belay?" "Taetigkeitsbericht". Safety Report, German Alpine Club, Munich.

Steele, G., 1976 "Attaching the rope to the climber". Climber and Rambler, February: 21-24.

Tarbuck, K.,1947 "My techniques with nylon rope". Rucksack Club J. 40: 234-246.

Wexler, A., 1950 "The theory of the belaying". Council of the Mountaineering Assoc., Wakefield and London.

Wirhed, R., 1984. Athletic Ability and the Anatomy of Motion. Wolfe Medical Publications, London.

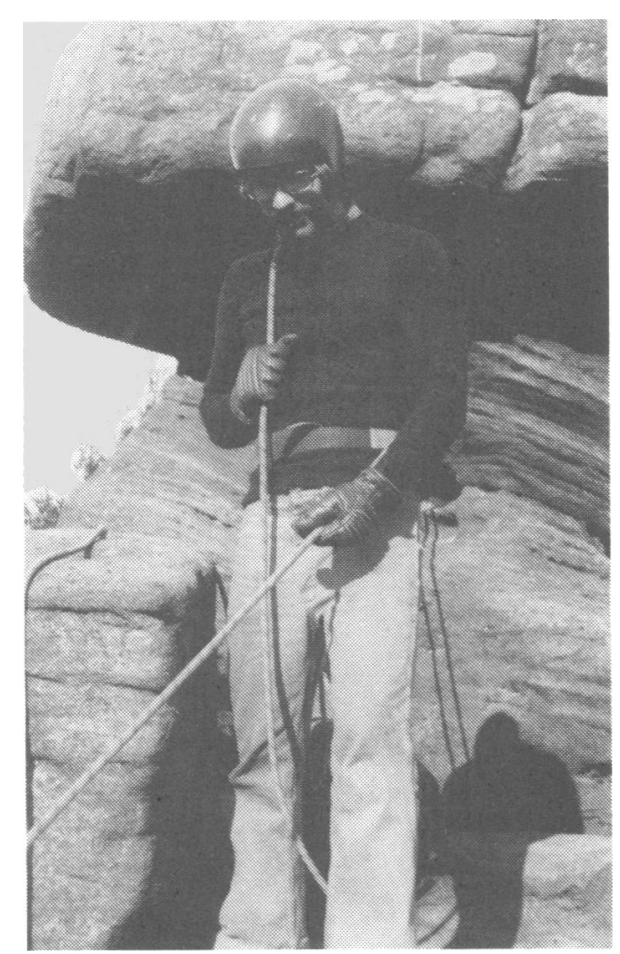

Plate 1: Shows the correct method of shoulder belay, the rope passing from the climber under the nearest armpit and over the farthest shoulder.

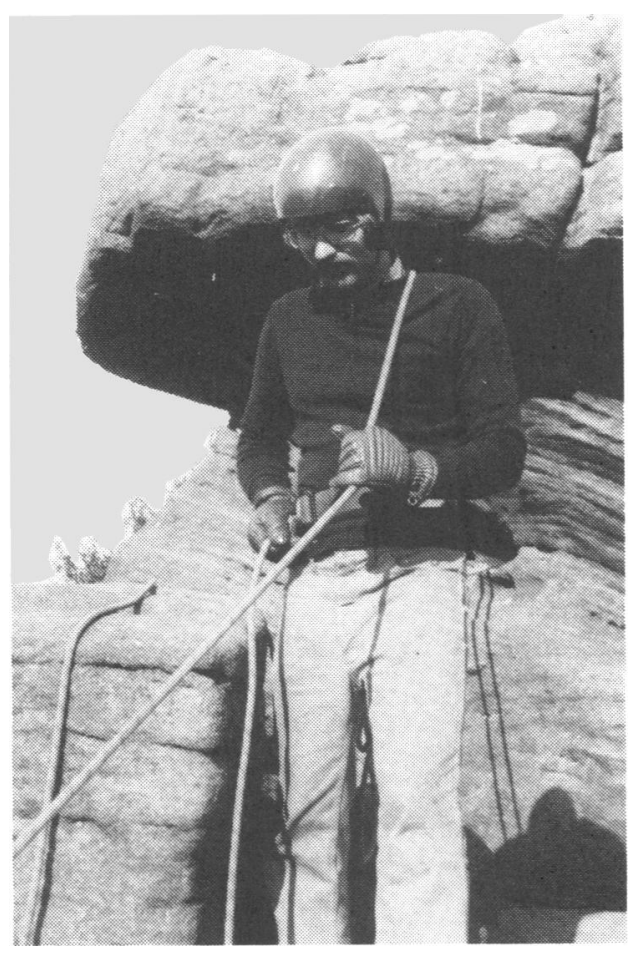

Plate 2: Shows the incorrect method of shoulder belay. If a fall should occur the belayer in this instance will pitch forward. 


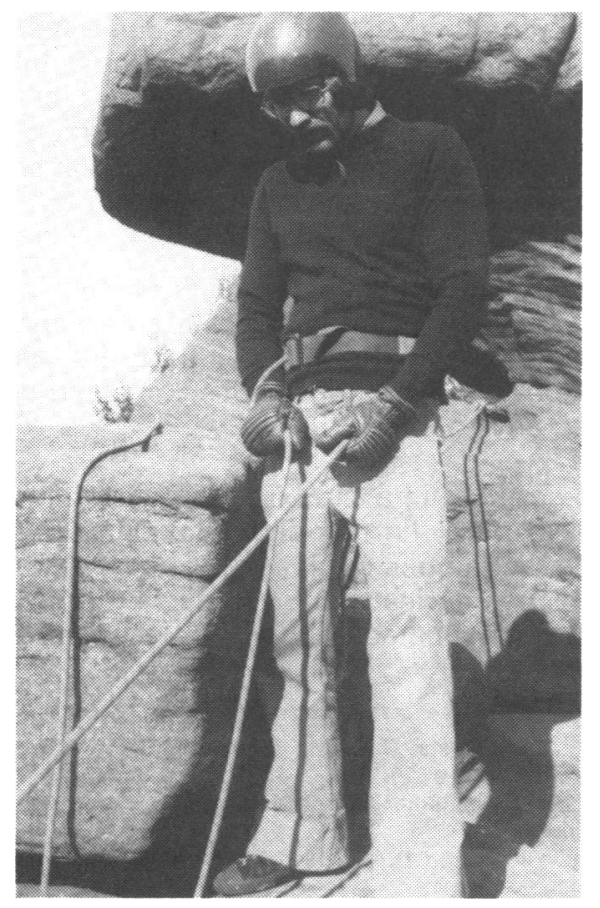

Plate 3: Shows the correct method of waist belay with the active rope first passing around the waist and a twist being taken around the farthest arm.

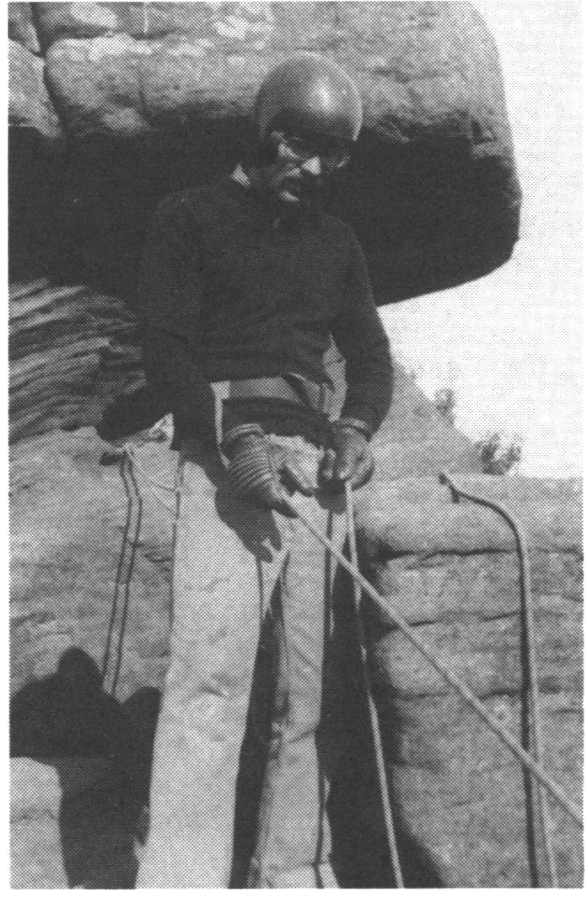

Plate 4: Shows the incorrect method of waist belay with the twist being taken around the lead arm. If a fall should occur the lead arm would suffer not only friction burns but also severe torsional stresses.

In all these plates, it should be noted that the belayer is dressed appropriately for the task. A protective helmet which will safeguard him against head injuries. Leather gloves and a thick woollen sweater which will protect his hands and body against friction burns generated by the heat in a sliding friction belay.

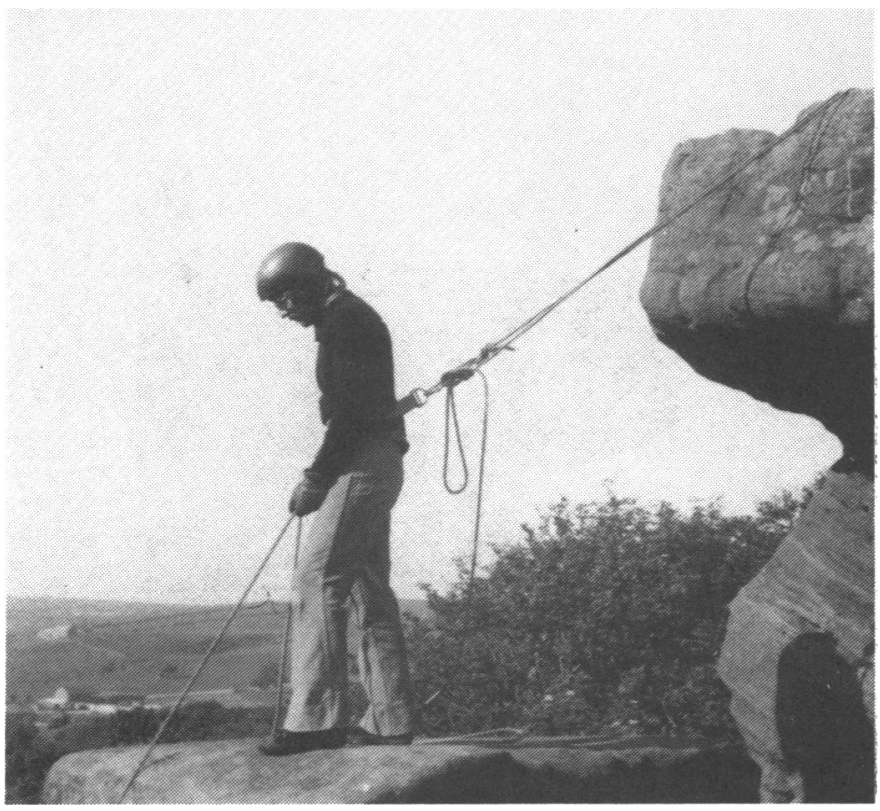

Figure 1 

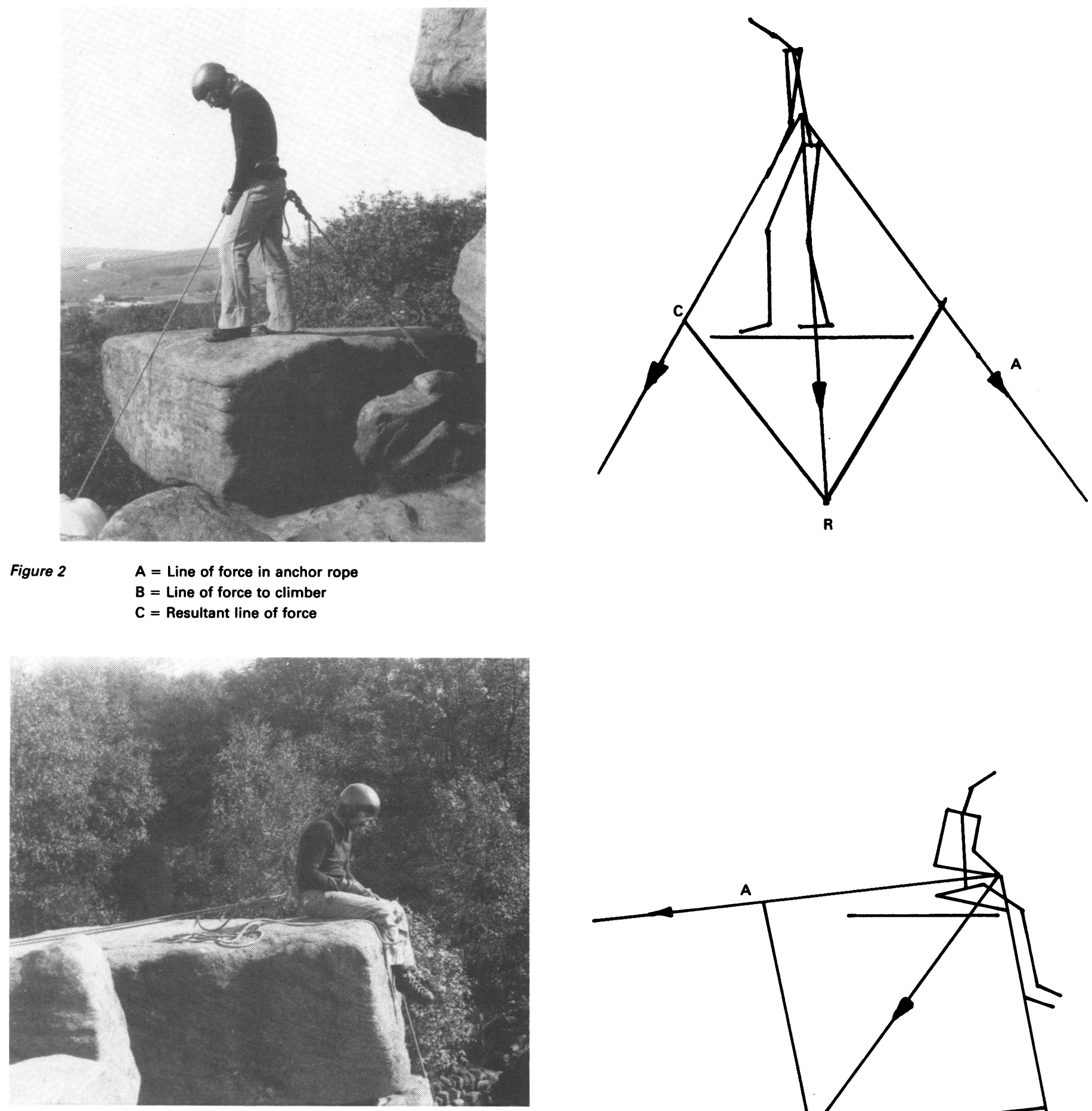

Figure 3
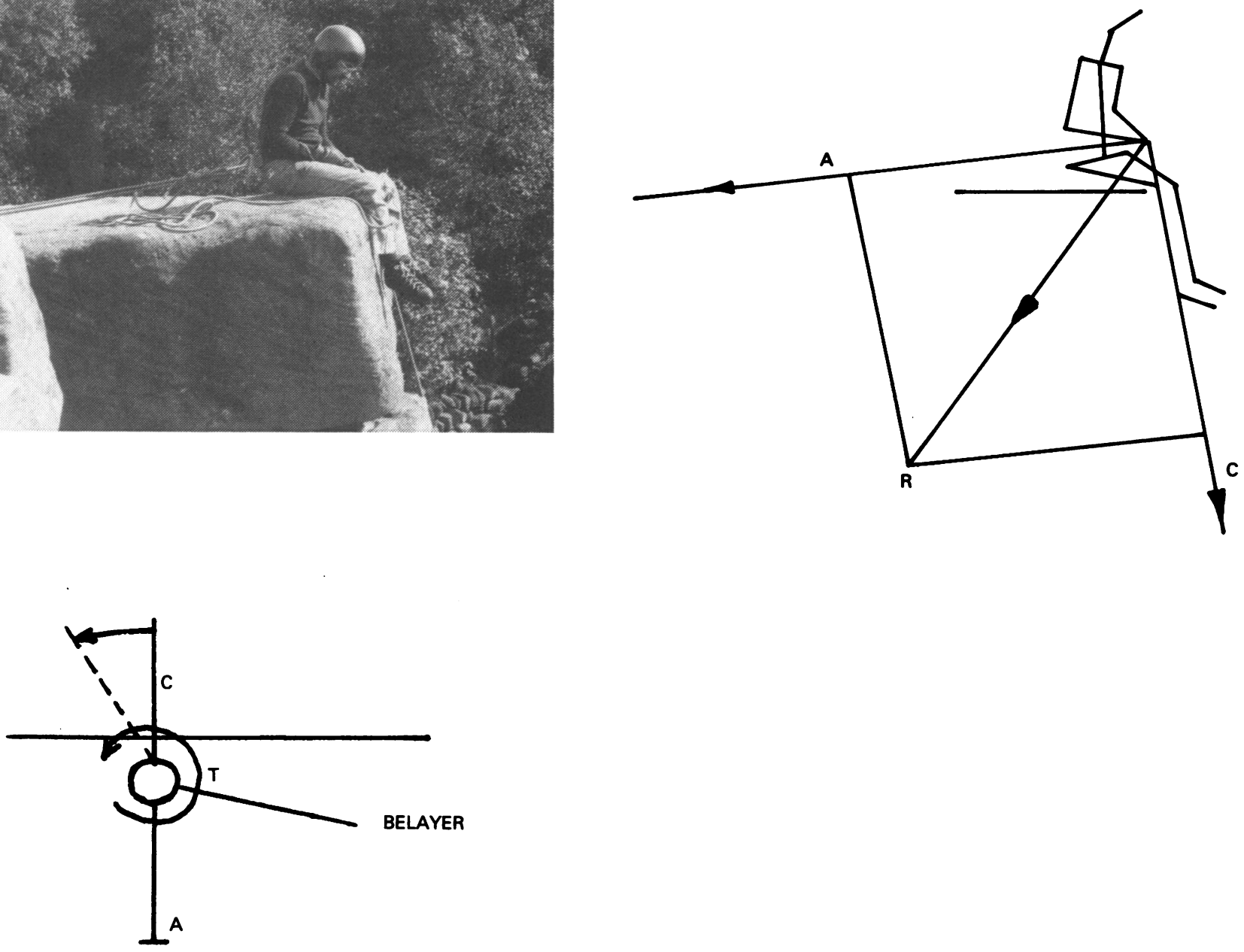